\title{
Temporal change in health-related quality of life: a longitudinal study in general practice 1999-2004
}

\author{
Michelle L Hazell, Julie A Morris, Mary F Linehan and Timothy L Frank
}

\begin{abstract}
Background

In order to assess and plan for changing healthcare needs, the lack of available information regarding temporal changes in the health-related quality of life of a population must be addressed.
\end{abstract}

Aim

This paper aims to describe such changes over 5 years in a general population.

\section{Design of study}

Longitudinal postal questionnaire study.

\section{Setting}

UK general practice.

\section{Method}

This was a longitudinal postal questionnaire study in two general practice populations, using the generic instrument EQ-5D to measure health-related quality of life. Individuals were included if they responded to three postal surveys in 1999, 2001, and 2004 and there were three consecutive values of EQ-5Dindex available between 1999 and 2004.

\section{Results}

A total of 2498 subjects were included in the study. After adjustment for potential confounders (including ageing), health-related quality of life declined

significantly over the observation period. The change in EQ-5Dindex was from 0.79 to 0.74 and for $E Q-5 D_{\text {vas }} 76.8$ to 73.3 ( $P$ for both trends $<0.001$ ).

\section{Conclusion}

Health-related quality of life deteriorated in these populations over 5 years. In an era of improvements in mortality, this has important implications for the use of health-related quality of life data in healthcare planning and resource allocation.

\section{Keywords}

chronic disease; EQ-5D; health related quality of life; temporal trend.

\section{INTRODUCTION}

To assess the changing health needs of a population and to evaluate the extent to which patients' healthrelated quality of life (HRQoL) benefits from health care, it is generally agreed that a systematic structured approach is needed. ${ }^{1}$ For this purpose, generic $H R Q 0 L$ measures such as EQ-5D have been developed. $^{2}$ In contrast to disease-specific instruments, these can compare quality of life in populations, regardless of disease.

EQ-5D has been used in cross-sectional studies in both general populations ${ }^{3-5}$ and those with specific morbidities. $^{6-9}$ So far, however, there has been no report of any long-term longitudinal study in the UK, although two British population surveys described follow-up of 1 year. ${ }^{1,10}$ A recent study from Sweden reported a deterioration over 4 years in HRQoL of women of all ages, and in younger men. ${ }^{11}$

\section{METHOD}

The aim of this study was to compare the temporal changes in health-related quality of life in three postal surveys. This study formed part of a larger long-term epidemiological study looking at a

ML Hazell, MBChB, PhD, honorary research associate; MF Linehan, $\mathrm{PhD}, \mathrm{BSc}$ (Hons), honorary research associate; TL Frank, MD, FRCGP, honorary reader, University of Manchester, Respiratory Research Group, School of Translational Medicine and NIHR, Translational Research Facility, Respiratory Medicine; JA Morris, BA(Hons), MSc, honorary senior lecturer, Department of Medical Statistics, University Hospital of South Manchester NHS Foundation Trust, Manchester.

Address for correspondence

Dr Timothy L Frank, University of Manchester, 2nd floor ERC, General Practice Research Unit, GP Research Unit, NorthWest Lung Research Centre, Wythenshawe Hospital, Southmoor Road, Manchester, M23 9LT.

E-mail: Timothy.Frank@manchester.ac.uk

Submitted: 4 March 2009; Editor's response: 5 May 2009; final acceptance: 13 July 2009.

(c)British Journal of General Practice 2009; 59: 839-843.

DOI: 10.3399/bjgp09X472890 


\section{How this fits in}

Health-related quality of life deteriorated in the general practice populations

over 5 years. In an era of improvements in mortality, this was unexpected and has important implications for the use of health-related quality of life data in healthcare planning and resource allocation. Although one Swedish study using $E Q-5 D_{\text {index }}$ which observed a similar deterioration in health status using two time periods was identified, there would appear to be no other reports of the use of EQ-5D over three time points. population of patients registered with two general practices in South Manchester focusing on respiratory symptoms (WYCAP). ${ }^{12}$ Two questionnaires, a respiratory questionnaire based on the European Community Respiratory Health Survey, ${ }^{13}$ and an EQ-5D, ${ }^{1,2}$ were sent to all adult patients registered with the general practices in three separate surveys in 1999, 2001, and 2004. ${ }^{12}$ EQ-5D consists of two parts. The first part records self-assessed health status according to five dimensions: mobility, self-care, usual activities, pain/discomfort, and anxiety/depression. Each dimension is divided into three levels: no problem, some problems, and severe problems. A unique health state can be expressed by combining the different level from each dimension. This is then transformed into a weighted health state index score (EQ-5D index) using a tariff of values derived from valuation exercises carried out in general populations. ${ }^{14}$ The second part records the responders' overall assessment of their health on a $20 \mathrm{~cm}$ visual analogue scale (EQ-5Dvas). In both cases, a larger number represents better HRQoL. Using information from EQ-5D, judgements can also be made about the most efficient way to use available resources to improve the health of the population.

The methodolology of these postal surveys and the practice demographics are described in previous publications..$^{12,15,16}$ The results from EQ-5D will be considered further here.

\section{Analysis}

Only those subjects with three consecutive values of EQ-5D index available between 1999 and 2004 were included in the present analyses. Mean EQ-5D index and $E Q-5 D_{\text {vas }}$ scores were calculated, and changes over time were determined by longitudinal analysis using a generalised estimating equation (GEE) regression model, which appropriately and efficiently assesses subject-specific temporal changes, implemented with STATA software. Significant changes and trends over time, with their associated confidence intervals (Cls), were derived from the coefficients of the GEE regression model, using the robust Huber-White sandwich estimator of variance. Adjustment was made for a number of possible confounding factors, namely age, sex, smoking status (current, ex, never), education beyond 16 years (yes/no) and degree level education (yes/no).

\section{RESULTS}

The response rate to the three postal surveys after adjustment for 'ghosts' was $69.4 \%$ in $1999,69 \%$ in 2001 , and $46.9 \%$ in 2004 . A total of 9447 subjects, for whom sufficient data were available to calculate $E Q-5 D_{\text {index }}$ for at least one survey, were considered for this study. For 2498 (26.4\%) of these, EQ-5Dindex was available for all three questionnaires and these were the subjects included in the present analyses. They were significantly older and had fewer ever-smokers than the excluded group, mean age 50.6 versus 41.7 years (difference 8.9 years, $95 \% \mathrm{Cl}=8.0$ to 9.8 years), proportion of ever smokers $60.9 \%$ versus $64.6 \%$ (difference $3.7,95 \% \mathrm{Cl}=1.2$ to 6.1 ).

Subjects included in the study were older than the general population sample used to derive UK population norms for EQ-5D, ${ }^{17}$ with the proportion aged $\geq 45$ years $61.6 \%$ versus $52.3 \%$ (difference $9.3 \%, 95 \% \mathrm{Cl}=6.7$ to 11.8 ). There was no significant difference in sex, with the proportion of males being $44.3 \%$ and $43.2 \%$ respectively (difference 1.1, 95\% $\mathrm{Cl}=-1.5$ to 13.6$)$. Mean $E Q-5 D_{\text {index }}$ was significantly lower in the study sample compared with the UK norms population: 0.79 versus 0.86 (difference 0.07 , $95 \% \mathrm{Cl}=0.06$ to 0.08 ).

Age, sex, and smoking status were all found to significantly affect both $E Q-5 D_{\text {index }}$ and $E Q-5 D_{\text {vas }}$ scores, but analysis of the effect of educational status on EQ-5D gave mixed results (Table 1). Age had a negative effect $(P<0.001)$, with an average decrease in EQ-5D index for each year of increase in age of 0.0048 and for EQ-5D vas of 0.294. On average, males had higher scores than females, with a difference of 0.034 on $E Q-5 D_{\text {index }}$ and 1.79 on $E Q-5 D_{\text {vas. }}$.

Ex-smokers and never smokers had higher HRQoL scores compared to current smokers, on both EQ$5 D_{\text {index }}$ and $E Q-5 D_{\text {vas. }}$.

There was a significant decline in mean EQ-5Dindex (Table 2) over the 5-year observation period, from 0.79 to $0.74,(P<0.001)$, with an estimated annual average decrease of 0.01 (95\% Cl $=0.008$ to 0.012$)$. This trend persisted after adjusting for age, sex, smoking status, and educational level in GEE regression analysis, with an adjusted annual average decrease of 0.0048 (95\% $\mathrm{Cl}=0.0028$ to 0.0068 ), $P<0.001$ (Table 2).

Similar results were found when $E Q-5 D_{\text {vas }}$ was examined, with a decrease from 76.6 to 73.3 over the observation period $(P<0.001)$, and an estimated 
Table 1. Changes in HRQoL by age, sex, smoking, and education with $95 \%$ confidence intervals $(\mathrm{Cl})$ and significance levels.

\begin{tabular}{lcccc} 
& $\begin{array}{c}\text { Difference in } \\
\text { EQ-5Dindex }(95 \% \mathrm{Cl})\end{array}$ & $P$-value & $\begin{array}{c}\text { Difference in adjusted } \\
\text { yearly difference in } \\
\text { EQ-5D vas }(95 \% \mathrm{Cl})\end{array}$ & $P$-value \\
\hline Yearly increase in age & $-0.0048(-0.0053$ to -0.0042$)$ & $<0.001$ & $-0.294(-0.332$ to -0.257$)$ & $P<0.001$ \\
\hline Male sex & $0.034(0.014$ to 0.053$)$ & 0.001 & $1.79(0.53$ to 3.05$)$ & 0.005 \\
\hline Ex versus current smoking & $0.034(0.015$ to 0.052$)$ & $<0.001$ & $2.57(1.14$ to 4.00$)$ & $<0.001$ \\
\hline Never versus current smoking & $0.064(0.042$ to 0.085$)$ & $<0.001$ & $6.19(4.71$ to 7.67$)$ & $<0.001$ \\
\hline Degree education & $-0.023(-0.043$ to -0.003$)$ & 0.025 & Not significant & 0.540 \\
\hline Continued education & Not significant & 0.190 & $1.46(0.30$ to 2.62$)$ & 0.014 \\
\hline
\end{tabular}

The P-values were derived from the GEE regression models, and correspond to the significance of the specific regression coefficients (using the robust Huber-White sandwich estimator of variance).

annual average decline of $0.696(95 \% \mathrm{Cl}=0.557$ to 0.836). This, too, remained significant after adjustment for the same possible confounding factors, with an adjusted annual average decrease of $0.365(95 \% \mathrm{Cl}=0.215$ to 0.515$), P<0.001$ (Table 2).

\section{DISCUSSION}

\section{Summary of main findings}

This study has shown a decline in HRQoL in a general population over a 5-year observation period. This remained significant even after adjusting for potential confounders: ageing of the population, sex, and smoking status, and applied whether a societal valuation of $\mathrm{HRQoL}$ (EQ-5D index derived from a combination of five dimensions) or an individual valuation ( $E Q-5 D_{\text {vas }}$ ) was considered. This is an important and unexpected finding, as socioeconomic conditions and affluence in the UK have generally improved and HRQoL could be expected to be better as these factors improve. Browning et al found that HRQoL improved in relation to income and education, but did not find an association between poor HRQoL and unemployment. ${ }^{18}$

There are several possible reasons for a decline in HRQoL over time. First, improvements in medical care have led to more people surviving events such as strokes and myocardial infarctions, with the effect of more people being alive but with increased overall morbidity and, therefore, reduced HRQoL. Secondly, expectations and perceptions regarding HRQoL may have changed; this may partially explain the greater decline seen on $\mathrm{EQ}-5 \mathrm{D}_{\text {vas, }}$ as this measure records the individuals status in relation to 'best imaginable health state'. This may be associated with the recent trend towards medicalisation of conditions (largely driven by the availability of treatments), ${ }^{19}$ for example, the lowering of blood pressure targets for hypertension means that more patients have a label for a disease that was not causing them any current symptoms. Thirdly, other factors that affect HRQoL but were not measured in these surveys may have changed, for example the prevalence of obesity. ${ }^{20}$

\section{Strengths and limitations of the study}

Selection bias must be considered when interpreting the study findings. Although the group included in the analyses was older and contained fewer smokers than the subjects excluded, the results were adjusted for these potential confounders. Response rates to the postal analysis from another paper ${ }^{21}$ on this study show responders in both 2001 and 2004 were older (mean 48.5 versus 37.6 years $P<0.001$ [2001]; 50.5 versus 38.8 years $P<0.001$ [2004]) and more likely to be female $(54.9 \%$ versus $44.9 \% \quad P<0.001$ [2001]; $55.3 \%$ versus $48.5 \% \quad P<0.001 \quad$ [2004]). Early responders were older, and more likely to be female, but less likely to smoke than those who responded to reminders. There was no important association between respiratory symptoms, and associated feature prevalence and stage of response. ${ }^{21}$ However, if those who are most ill are least capable and therefore least likely to respond to repeated surveys (or indeed to any postal survey), the resulting response bias would in fact cause an underestimate of the decrease in HRQoL. Ceiling effects on EQ-5D (particularly due to the modelling algorithm for calculating EQ-5Dindex), as reported elsewhere, ${ }^{22-24}$ may also have contributed to this potential underestimate.

Table 2. Trends in mean EQ-5D index and $E Q-5 D_{\text {vas }}$ over time.

\begin{tabular}{lccccc} 
All subjects & 1999 & 2001 & 2004 & P-value & $\begin{array}{c}\text { Adjusted yearly } \\
\text { decrease }(95 \% \mathrm{Cl})\end{array}$ \\
\hline$n$ & 2498 & 2498 & 2498 & & \\
Mean EQ-5Dindex & 0.79 & 0.78 & 0.74 & $<0.0010 .0048(0.0028$ to 0.0068) \\
SD & 0.28 & 0.28 & 0.30 & & \\
\hline$n$ & 2429 & 2436 & 2368 & & \\
Mean EQ-5D vas & 76.6 & 75.9 & 73.3 & $<0.001$ & $0.696(0.557$ to 0.836$)$ \\
SD & 19.5 & 19.4 & 19.4 & & \\
\hline
\end{tabular}




\section{Comparison with existing literature}

There would appear to be no other reports of the use of EQ-5D over three time points, which adds considerably to the reliability of assessments of trend. ${ }^{25}$ However, a Swedish study using EQ-5D index also observed a smaller deterioration in health status over time in both men and women of all age groups. ${ }^{11}$

In addition to statistical significance, it is also essential to assess the importance of the changes found; given the relatively large population studied, small degrees of change could be statistically significant. Although some studies have addressed this problem and examined minimal important difference (MID) ${ }^{26}$ and clinically significant change ${ }^{27}$ in HRQoL, they have generally included only subjects who had one specific morbidity. Extrapolating figures from a study comparing the respiratory diseasespecific St George's respiratory questionnaire (SGRQ), ${ }^{27}$ with EQ-5D, a clinically significant change in $E Q-5 D_{\text {index }}$ would be 0.08 and in $E Q-5 D_{\text {vas }} 9.08 .{ }^{28}$ The MID for EQ-5D vas has not been widely studied, but one estimate is as low as 3.0. ${ }^{29}$ There are few reports, so far, of what changes are important in a general population, which includes a majority of healthy people in addition to those with a number of different single and multiple pathologies.

\section{Implications for future research or clinical practice}

The use of a generic measure of HRQoL, in this case $E Q-5 D$, enabled the assessment of temporal change to be made irrespective of specific morbidity. HRQoL measures such as EQ-5D are often used to measure the benefit of healthcare interventions, and to ascribe economic value to different health states by conversion to utilities. This is a vital step in assessment of clinical effectiveness, and is recommended by bodies such as the National Institute for Health and Clinical Excellence (NICE). ${ }^{30}$ The same measure could be used to compare temporal change in HRQoL of groups of people with different morbidities and also multiple pathologies in one or several populations.

Differences in the rate of change between different morbidities and populations must be taken into account in assessing and planning healthcare needs and resource provision for the population, and it is therefore important to corroborate these unexpected findings of a decline in HRQoL with further research into the temporal change.

\section{Funding body}

The surveys were funded by grants from the NHS Executive (Ref RDO/28/1/01), Allen and Hanbury Ltd, Manchester Airport plc, and Astra Zeneca plc. None of the funding bodies had any involvement in the collection or analysis of data or in the preparation and decision to submit manuscripts for publication

\section{Ethical approval}

Ethical approval for the three surveys was obtained via South Manchester Local Research Ethics Committee

\section{Competing interests}

Michelle $L$ Hazell has received a fee from Boehringer Ingelheim for speaking, and travel grants from GSK, Boehringer Ingelheim, and MSD. Julie A Morris has no conflicts of interest; Mary F Linehan has received travel grants from GSK. Timothy Frank has received fees from GSK, Boehringer Ingelheim, Schering Plough, and Astra Zeneca for speaking, funds for research from GSK, Boehringer Ingelheim, MSD, and Schering Plough, funds for consultancy from GSK and Pharmacia, and travel grants from GSK, Boehringer Ingelheim, Astra Zeneca, Chiesi Pharmaceuticals, and MSD

\section{Acknowledgements}

The authors would like to thank the patients and staff at Bowland and Tregenna surgeries and the staff at the North West Lung Centre who made this research possible.

\section{Discuss this article}

Contribute and read comments about this article on the Discussion Forum: http://www.rcgp.org.uk/bjgp-discuss

\section{REFERENCES}

1. Kind P, Hardman G, Leese B. Measuring health status: information for primary care decision making. Health Policy 2005; 71(3): 303-313.

2. EuroQol Group. EuroQol - a new facility for the measurement of health-related quality of life. Health Policy 1990; 16(3): 199-208.

3. Ko Y, Coons SJ. Self-reported chronic conditions and EQ-5D index scores in the US adult population. Curr Med Res Opin 2006; 22(10): 2065-2071.

4. Saarni SI, Harkanen T, Sintonen H, et al. The impact of 29 chronic conditions on health-related quality of life: a general population survey in Finland using 15D and EQ-5D. Qual Life Res 2006; 15(8): 1403-1414.

5. Lubetkin EI, Jia H, Franks P, Gold MR. Relationship among sociodemographic factors, clinical conditions, and health-related quality of life: examining the EQ-5D in the US general population. Qual Life Res 2005; 14(10): 2187-2196.

6. Darlington AS, Dippel DW, Ribbers GM, et al. Coping strategies as determinants of quality of life in stroke patients: a longitudinal study. Cerebrovasc Dis 2007; 23(5-6): 401-407.

7. Lotery AJ, Xu X, Zlatava G, Loftus J. Burden of illness, visual impairment, and health resource utilisation of patients with neovascular age-related macular degeneration: results from the United Kingdom cohort of a five-country cross-sectional study. Br J Ophthalmol 2007; 91(10): 1303-1307.

8. Gottberg K, Einarsson U, Ytterberg C, et al. Health-related quality of life in a population-based sample of people with multiple sclerosis in Stockholm County. Mult Scler 2006; 12(5): 605-612.

9. Punekar YS, Rodriguez-Roisin R, Sculpher M, et al. Implications of chronic obstructive pulmonary disease (COPD) on patients' health status: a western view. Respir Med 2007; 101(3): 661-669.

10. Cuthbertson BH, Scott J, Strachan M, et al. Quality of life before and after intensive care. Anaesthesia 2005; 60(4): 332-339.

11. Burstrom K, Johannesson M, Rehnberg C. Deteriorating health status in Stockholm 1998-2002: results from repeated population surveys using the EQ-5D. Qual Life Res 2007; 16(9): 1547-1553.

12. Frank PI, Wicks PD, Hazell ML, et al. Temporal change in the prevalence of respiratory symptoms and obstructive airways disease 1993-2001. Br J Gen Pract 2005; 55(517): 596-602.

13. Burney PG, Luczynska C, Chinn S, Jarvis D. The European Community Respiratory Health Survey. Eur Respir J 1994; 7(5): 954-960.

14. Dolan P. A social tariff for EuroQol: results from a UK general population survey. Discussion Paper. York: Centre for Health Economics, 1995.

15. Frank P, Ferry S, Moorhead T, Hannaford P. Use of a postal questionnaire to estimate the likely under-diagnosis of asthma-like illness in adults. Br J Gen Pract 1996; 46(406): 295-297.

16. Frank TL, Heyworth I, Hazell ML, Linehan MF. How do common chronic conditions affect health related quality of life? Br J Gen Pract 2009; 59: 833-838. 
17. Kind P, Hardman G, Macran S. UK population norms for EQ-5D. Discussion Paper 172. York: Centre for Health Economics, 1999.

18. Browning CR, Cagney KA, Wen M. Explaining variation in health status across space and time: implications for racial and ethnic disparities in self-rated health. Soc Sci Med 2003; 57(7): 1221-1235.

19. Moynihan R, Henry D. The fight against disease mongering: generating knowledge for action. PLoS Med 2006; 3(4): e191.

20. Sach TH, Barton GR, Doherty M, et al. The relationship between body mass index and health-related quality of life: comparing the EQ-5D, EuroQol VAS and SF-6D. Int J Obes 2007; 31(1): 189-196.

21. Hazell ML, Morris JA, Linehan MF, et al. Factors influencing the response to postal questionnaire surveys about respiratory symptoms. Prim Care Respir J 2009; 18(3): 165-170.

22. Macran S, Weatherly H, Kind P. Measuring population health: a comparison of three generic health status measures. Med Care 2003 41: $218-231$.

23. Coons SJ, Rao S, Keininger DL, Hays RD. A comparative review of generic quality-of-life instruments. Pharmacoeconomics 2000; 17(1): $13-35$.

24. Johnson JA, Pickard AS. Comparison of the EQ-5D and SF-12 health surveys in a general population survey in Alberta, Canada. Med Care 2000; 38(1): 115-121.

25. Burney P. The changing prevalence of asthma. Thorax 2002; 57(suppl II): ii36-ii39.

26. Walters SJ, Brazier JE. Comparison of the minimally important difference for two health state utility measures: EQ-5D and SF-6D. Qual Life Res 2005; 14: 1523-1532.

27. Jones PW. Interpreting thresholds for a clinically significant change in health status in asthma and COPD. Eur Respir J 2002; 19(3): 398-404.

28. Hazell ML. Health related quality of life in adults with respiratory symptoms. [PhD thesis]. Manchester: Manchester Metropolitan University, 2006.

29. Barton GR, Sach TH, Doherty M, et al. An assessment of the discriminative ability of the EQ-5D(index), SF-6D, and EQ VAS, using sociodemographic factors and clinical conditions. Eur J Health Econ 2008; 9(3): 237-249.

30. National Institute for Health and Clinical Excellence. Guide to the methods of technology appraisal. London: National Institute for Health and Clinical Excellence, 2004. 